\title{
Effect of temperature and apparent liquid viscosity on the hydrodynamics of liquid-solid tapered inverse fluidized bed: experimental studies compared with empirical models
}

\author{
H. Upender ${ }^{1} \cdot \mathrm{K}$. Anand Kishore ${ }^{1}$
}

Received: 10 January 2020 / Accepted: 27 February 2020 / Published online: 12 March 2020

(c) Springer Nature Switzerland AG 2020

\begin{abstract}
In the present work, immersed heater to bed heat transfer coefficient and related hydrodynamics were determined along with different angles ( 7.85 and 6.8) of the tapered inversed fluidized bed. Carboxyl methylcellulose was used to change the water viscosity by using a power-law model. The hydrodynamics was compared for two different angles of beds. Furthermore, minimum fluidization velocities were carried out for different liquid apparent viscosities and different angles of beds and compared with previous models. The heat transfer coefficient was found to be increasing with liquid velocity and bed voidage, respectively, and it was also found that the bed voidage is high for a high diameter of particles. The correlation was developed between the bed expansion ratio and independent parameters by response surface methodology in design expert software v.9.
\end{abstract}

Keywords Tapered inverse fluidized bed $\cdot$ Minimum fluidization velocity $\cdot$ Bed voidage $\cdot$ Heat transfer $\cdot$ Apparent viscosity

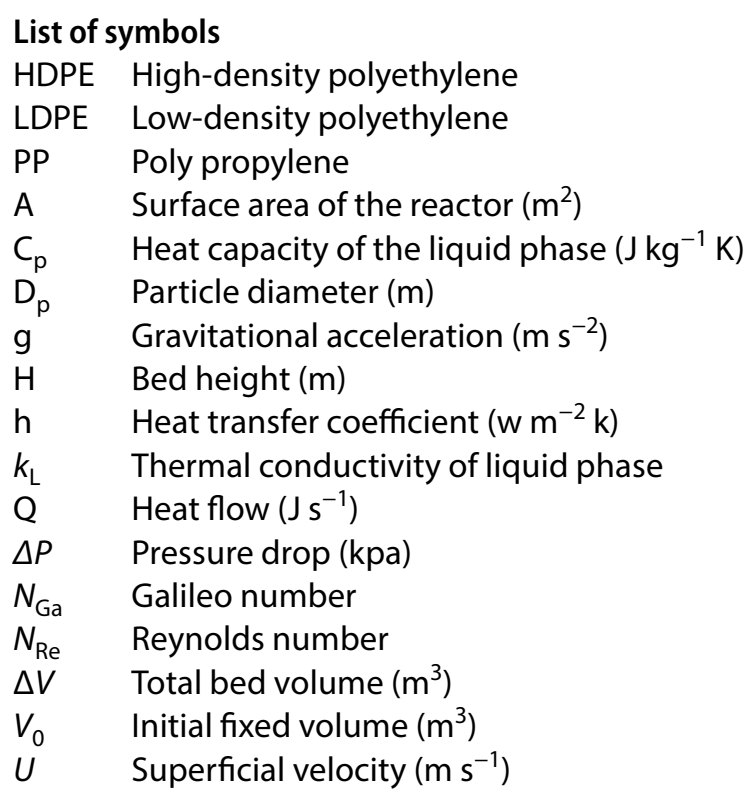

$\begin{array}{ll}\text { HDPE } & \text { High-density polyethylene } \\ \text { LDPE } & \text { Low-density polyethylene } \\ \mathrm{PP} & \text { Poly propylene } \\ \mathrm{A} & \text { Surface area of the reactor }\left(\mathrm{m}^{2}\right) \\ \mathrm{C}_{\mathrm{p}} & \text { Heat capacity of the liquid phase }\left(\mathrm{J} \mathrm{kg}^{-1} \mathrm{~K}\right) \\ \mathrm{D}_{\mathrm{p}} & \text { Particle diameter }(\mathrm{m}) \\ \mathrm{g} & \text { Gravitational acceleration }\left(\mathrm{m} \mathrm{s}^{-2}\right) \\ \mathrm{H} & \text { Bed height }(\mathrm{m}) \\ \mathrm{h} & \text { Heat transfer coefficient }\left(\mathrm{w} \mathrm{m}^{-2} \mathrm{k}\right) \\ k_{\mathrm{L}} & \text { Thermal conductivity of liquid phase } \\ \mathrm{Q} & \text { Heat flow }(\mathrm{J} \mathrm{s}) \\ \Delta P & \text { Pressure drop }(\mathrm{kpa}) \\ N_{\mathrm{Ga}} & \text { Galileo number } \\ N_{\mathrm{Re}} & \text { Reynolds number } \\ \Delta V & \text { Total bed volume }\left(\mathrm{m}^{3}\right) \\ V_{0} & \text { Initial fixed volume }\left(\mathrm{m}^{3}\right) \\ U & \text { Superficial velocity }\left(\mathrm{m} \mathrm{s}^{-1}\right)\end{array}$

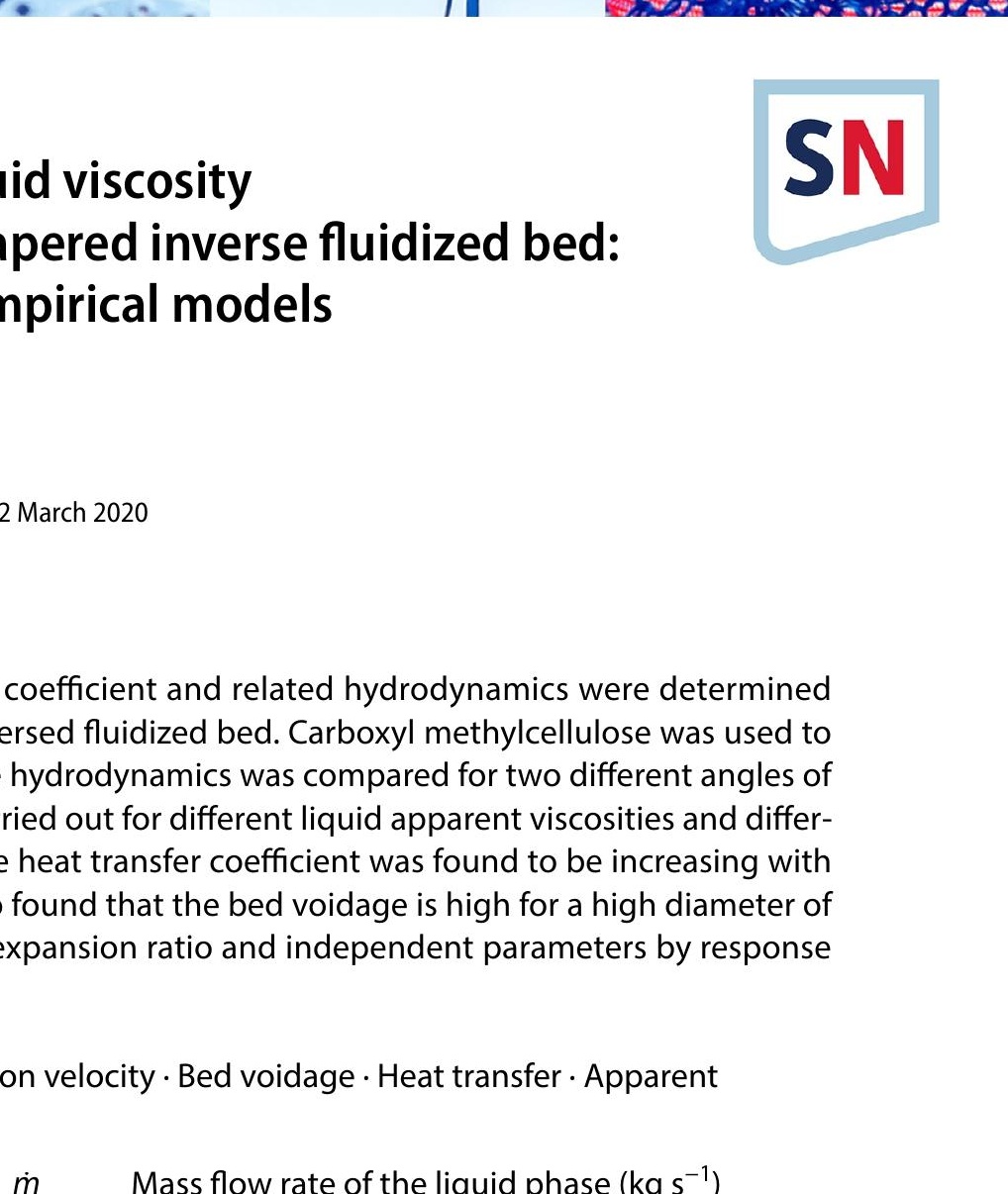

$\dot{m} \quad$ Mass flow rate of the liquid phase $\left(\mathrm{kg} \mathrm{s}^{-1}\right)$ Heat flow rate $\left(\mathrm{J} \mathrm{s}^{-1}\right)$

q Heat flow rate $\left(\mathrm{J} \mathrm{s}^{-1}\right)$

$T \quad$ Temperature (C)

Greek letters

$\varepsilon \quad$ Solid voidage

a Bed angle

$\rho \quad$ Density $\left(\mathrm{kg} / \mathrm{m}^{3}\right)$

$\mu \quad$ Apparent viscosity $\left(\mathrm{kg} \mathrm{m}^{-1} \mathrm{~s}\right)$

Subscripts

s Solid phase

I Liquid phase

h Heater surface

m Mean value

o Steady state

H. Upender, Upender07053@gmail.com | 'Department of Chemical Engineering, National Institute of Technology, Warangal 506004, India. 


\section{Introduction}

In separation techniques, liquid-solid inverse fluidization and hydrodynamic characteristics studies have been described for straight cylindrical or columnar inverse fluidized beds, even if a desirable part of the inverse fluidized beds has inclined walls or a tapered top section. A velocity gradient enters from the top of the bed in the axial direction and exits from the bottom of the bed with high energy consumption, power saving and easy refluidization in case of power failure, when compared to normal fluidization. Due to this behavior, tapered inverse fluidized beds have found full applications in many industrial processes, such as oil separation from water by using aerogels [1], formation and growth of biofilm thickness, reduction of COD, BOD, TOC [2]. Minimum fluidization is an essential parameter in the fluidization systems and varies from parameter to parameter [3]. By using fluidization techniques in bioreactors, there is the utilization of small particles with a large surface area when it allows higher specific reaction rates [4]. The minimum fluidization velocity depends on the initial bed heights, density of particles, and the diameter of the particles and viscosity of liquid media used [5]. Minimum fluidization velocity and pressure drops will also depend on the shape of beds used for the experiments [6]. Generally, parameters like hydraulic retention time, bio-carriers, reactor aspect ratio, superfacial gas velocity, superficial liquid velocity, bed expansion, and mass transfer coefficient affect the performance of a three-phase fluidized-bed bioreactor (TPIFB) [7]. The biofilm bed porosity depends on different flow rates and shape of the particles [8]. The mass transfer $(\mathrm{kLa})$ in an inverse three-phase fluidized bed increased with increasing gas velocity [9]. RTD studies of tracer (solids used as a tracer) were determined by CFD simulations and tested experimentally in conventional fluidized bed [10].

The findings of the hydrodynamics of three phases of inverse fluidized bed by sending gas into the sparger will assure better fluidization on the solids, and fluidization depends on different dimensions of the gas sparger [11]. In wastewater treatment, degradation of waste depends on time, superficial gas velocity, aspect ratio, and different ratios of settled bed volume to bed working volume $(\mathrm{Vb} /$ $\mathrm{Vr}$ ) [12]. To find the hydrodynamics of three-phase inverse fluidized bed, the pressure drop per unit length will be increased by increasing liquid flow rate and reaches a maximum and then decreased with further increasing liquid flow rate as the bed expands [13]. In the inverse fluidizedbed bioreactor, the wastewater treatment was depended on the organic loading rate, hydraulic retention time, and effluent concentrations [14]. It was observed that in the inverse fluidized bed, the voidage of solid particles independent of the number of solids and depended on the liquid velocity [15]. In the three-phase inverse fluidized bed, adding wetting agent to the downflow of liquid will avoid the hysteresis effect of hydrodynamic system between the inverse fluidization and refluidization; the minimum fluidization voidage for three-phase system was lower than that of two-phase system because local agitation by the gas bubbles causes bed compaction near the minimum liquid fluidization velocity, and it was observed that the minimum fluidization velocity decreased with gas velocity, sometimes shows concave-downward, sometimes concave-upward and sometimes S-shaped behaviors [16]. In the inverse three-phase fluidized bed, the liquid entering the reactor bed often carries gas bubbles, and when bubbles enter an up-flow fluidized bed they leave the bed rapidly because the directions of its free rise are the same as the direction of the liquid flow. Therefore, it does not change the significant hydrodynamic state of the bed; if the bubbles move downwards together with the liquid, since gas bubbles accumulate in the inverse fluidized bed, they affect the hydrodynamic measurement [17]. In the two-phase (solid-liquid) and the three-phase (solid-liquid-gas) inverse fluidized beds, it was observed that the different types of fluidization regimes would be found with gas velocity in the bed voidage profiles [18]. In the rectangular shape of the three-phase inverse fluidized bed, it was observed that the temperature effects on the bed voidage and heat transfer coefficient would be increased with gas velocity and liquid velocity and with bed voidage [19]. The heat transfer coefficient depends on the diameter of the particles in the swirling fluidizedbed reactor [20]. The packed bed with particles of smaller size has a lower coefficient of heat transfer. The average heat transfer rate from the fluidizing gas to the solids was observed to increase with an increasing average velocity at pulsation amplitudes low to moderately high. The fluidized bed's temperature homogeneity increased with an increasing pulsation amplitude, but the average heat transfer rate decreased when the maximum gas velocity at the end of each pulsation period became too large [22]. At the higher gas flow rate, the high heat transfer coefficient for different biomass particles will be obtained, which may lead to better mixing of gas-solids in a pulsed fluidized bed with a tapered bottom [23]. Pulsed fluidization is a particular form of fluidized bed processes in which the gas flow rate is varied with time periodically. Inlet airflow pulsation improves gas-particle interaction in fluidized beds by raising gas by passage, and channeling in this type of operation heat transfer rates is high at higher pulsation frequency because smaller bubbles are formed at this frequency [24]. Sahu et al. [25] found the operating temperature effects on the hydrodynamics studies of dense gas-solid flow inside the reactor. They claimed that 
the heat transfer affects the minimum fluidization velocity, voidage profiles, and axial velocity of the solids.

Up to now, many works were done on the hydrodynamic studies of two and three phases in the rectangular shape of fluidized beds. In this study, to find the effect of hydrodynamics at different temperatures and viscosity of the liquid, different-angles of tapered beds were used in this study. The experimental results were compared with the empirical models. The correlation was developed for bed expansion ratio in terms of independent parameters by using response surface methodology (RSM) in design expert software v.9. The main novelty of this method is to find the minimum fluidization velocity profile, bed expansion profile, bed voidage profile, and pressure drop profiles by changing the temperature of a liquid, viscosity of a liquid, angle of beds, the diameter of solids, and density of solids. All these the experiments were carried out in the tapered inverse fluidized bed; all the results were compared with the design expert software, and some of experimental results were compared with the empirical models.

\section{Experimental setup}

Experiments were performed in the two-phase system in different angles of the tapered inverse fluidized bed made up of an acrylic column $0.59 \mathrm{~m}$ high, $0.09 \mathrm{~m}$ top diameter and $0.25 \mathrm{~m}$ bottom diameter. The schematic diagram of the experimental setup is represented in Fig. 1.
For heating purposes, a heater $(25.4 \mathrm{~mm}$ o.d. $\times 1.5 \mathrm{~m}$ length) was vertically placed at the center in the fluidized bed. The temperatures at the heater surface and the fluidized-bed proper were measured by the iron-constantan thermocouples (J type), which were mounted on the column at $20 \mathrm{~cm}$ height intervals. This heater was connected to a temperature controller that was used to control and maintain continuously the desired temperatures.

A significant change in the fluidizing bed took place for different fluid velocities. In that process, the pressure drop was also calculated in the bed from one consistent fluidizing state to another as a function of liquid velocity. When a new consistent state was reached, the temperatures were measured again. The equation below was used to calculate the heat transfer coefficient

$h=\frac{q}{A\left(T_{\mathrm{h}}-T_{\mathrm{m}}\right)}$

$q$ is the heat flux, acquired from DC electricity supply, and the temperature difference between the dipped in water heater and bed is determined with the aid of

$T_{\mathrm{h}}-T_{\mathrm{m}}=\frac{\int_{0}^{R} U(r)\left[\left(T_{\mathrm{h}}-T_{.}(r)\right)\right] r \mathrm{~d} r}{\int_{0}^{R} U(r) r \mathrm{~d} r}$

The velocity distribution in radial direction expression changed from suspect to uniform to that proposed for the fully advanced flow in an inverse fluidized bed. The energy used to determine the heat flux was
Fig. 1 Schematic diagram of tapered inverse fluidized bed

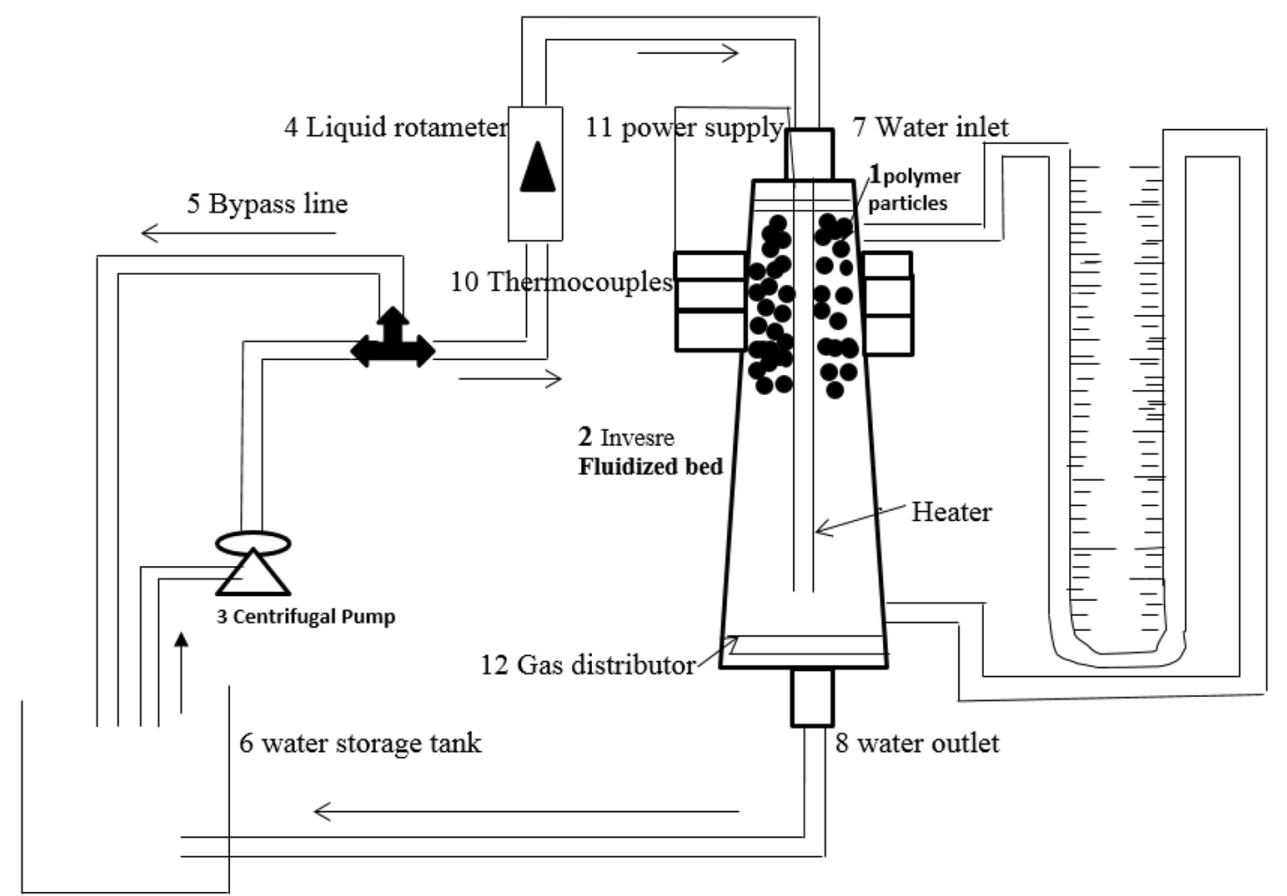


$q=\dot{m} C_{\mathrm{pl}}\left(T_{\mathrm{mo}}-T_{\mathrm{mi}}\right)$

\section{Results and discussions}

\subsection{Measurement of heat transfer}

The radial temperature profiles along the bed were observed; it was seen that the temperature at the heater surface was much steeper than that of bed proper. The heat transfer coefficient was calculated in different angles of beds at different apparent viscosities of liquid flow rates using the above Eq. (1).

The Nusselt number Eq. (4) was calculated in terms of bed voidage Eq. (9) from the Wen-Yu and heat transfer coefficient.

$\mathrm{Nu}=h d_{\mathrm{p}} \frac{\left(1-\varepsilon_{\mathrm{s}}\right)}{K_{l} \varepsilon_{\mathrm{s}}}$

\subsubsection{Effect of bed voidage on heat transfer coefficient}

From Fig. 2, it was observed that the particles holdup decreased with increasing bed voidage; therefore, the heat transfer coefficient also exhibited maximum value with an increase in the bed voidage, and it varied with different density of materials.

The heat transfer coefficient was affected by the liquid velocity, as shown in Fig. 3. As anticipated, the $h$ value increased by increasing the liquid velocity. The cause may be due to the decrease in the particle holdup and the alteration of solids drift regime. In other attributed words, we can say that the solid holdup decreases unusually

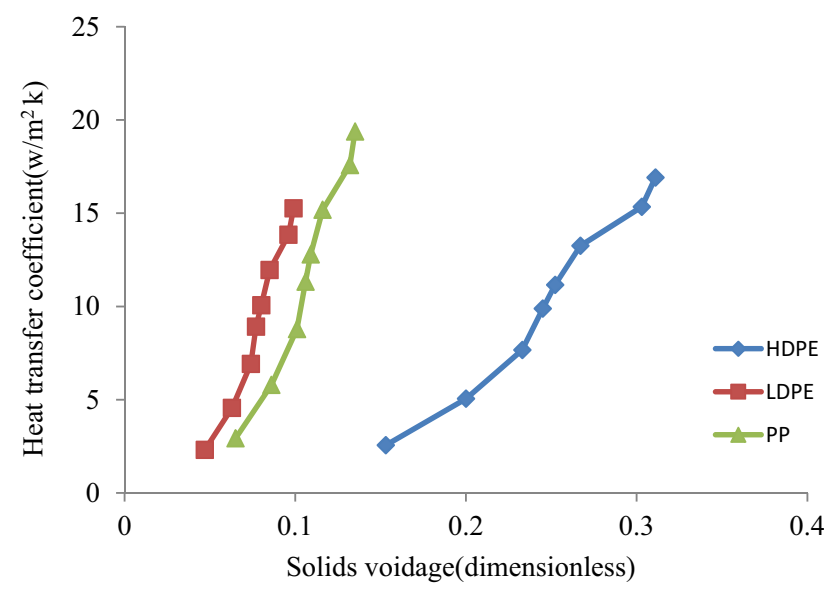

Fig. 2 Effect of heat transfer coefficient with bed voidage for the different densities of materials at $H_{0}=0.04 \mathrm{~m}$

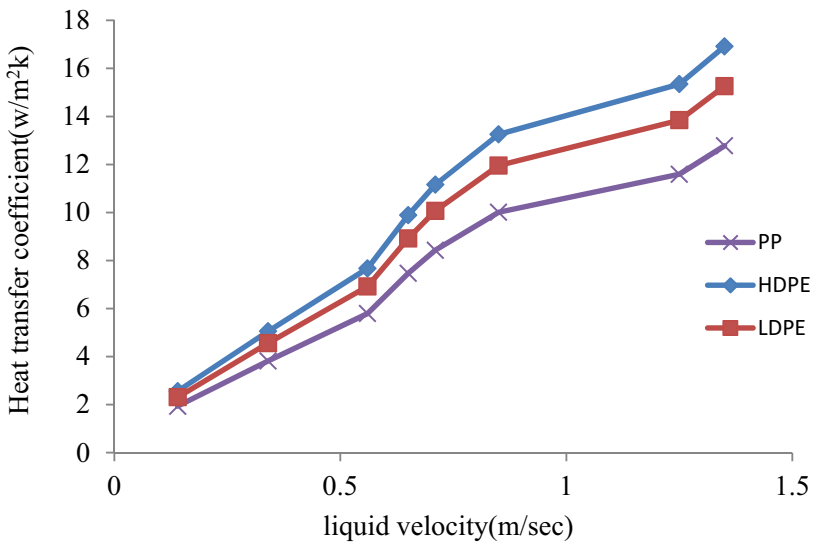

Fig. 3 Effect of liquid velocity on the heat transfer coefficient at the different densities of materials at $H_{0}=0.04 \mathrm{~m}$

with increasing liquid velocity in the higher range of liquid velocity. This results in inadequate contact among the fluidized solids and the heater surface; consequently, the liquid thin film across the heater surface cannot be eroded efficaciously. Consequently, h decreases with an additional increase in liquid velocity. Further, the turbulence inside the bulk vicinity could be decreased by lowering solid holdup in the higher liquid velocity range.

The effect of liquid velocity on bed expansion at different temperatures can be seen in Fig. 4. By increasing the temperature of the liquid, the bed expanded profoundly at high temperatures. The cause may be defined through the decrease in the particle holdup, and the transition of the solids drift regime due to the viscous nature of water at low temperature. In other words, the solid voidage and flow regime increased in high-temperature conditions.

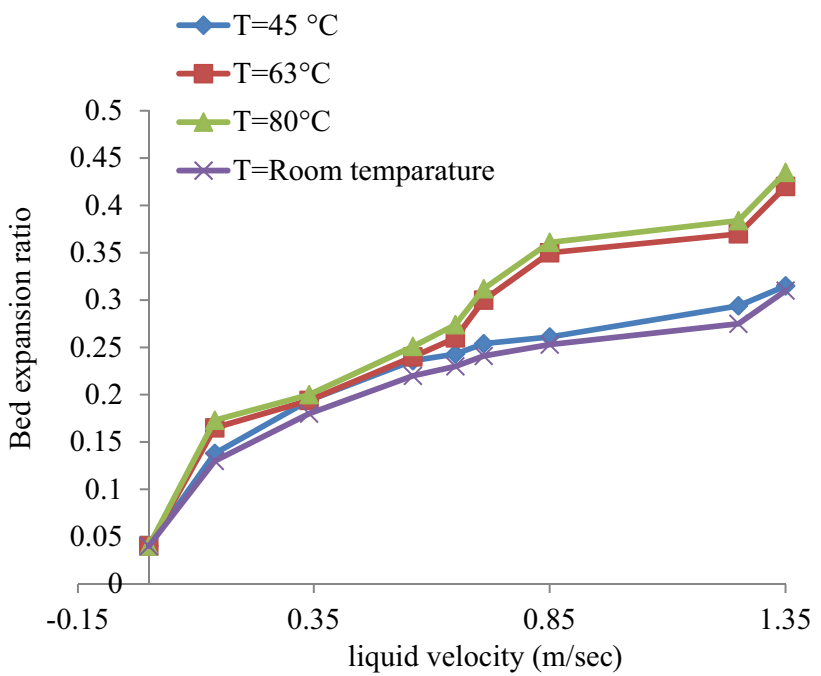

Fig. 4 Effect of temperature on bed expansion with the apparent liquid viscosity $0.014 \mathrm{~kg} / \mathrm{m} \mathrm{s}$ at $H_{0}=0.04 \mathrm{~m} \mathrm{HDPE}$ 


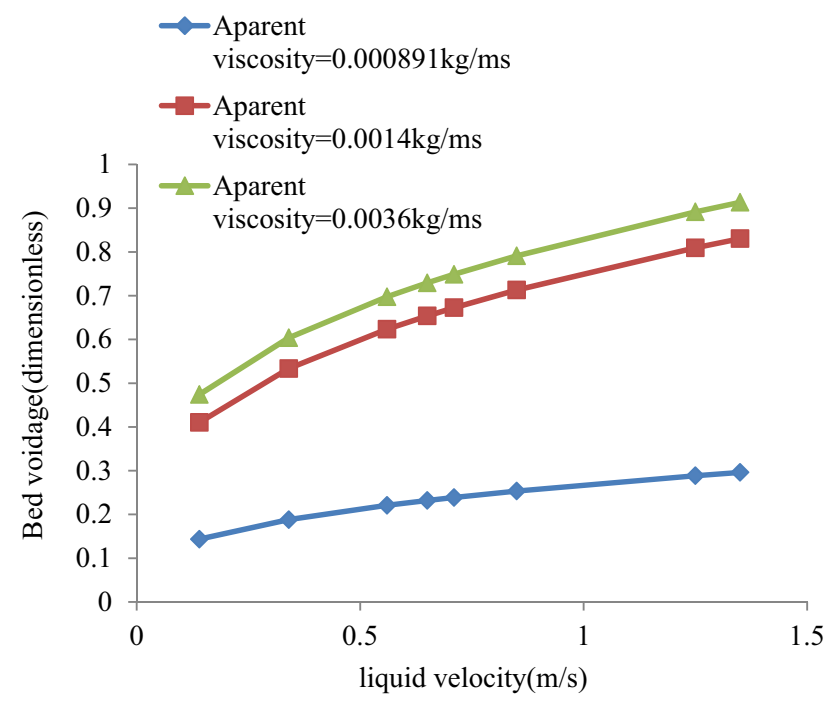

Fig. 5 Effect of apparent liquid viscosity on bed voidage

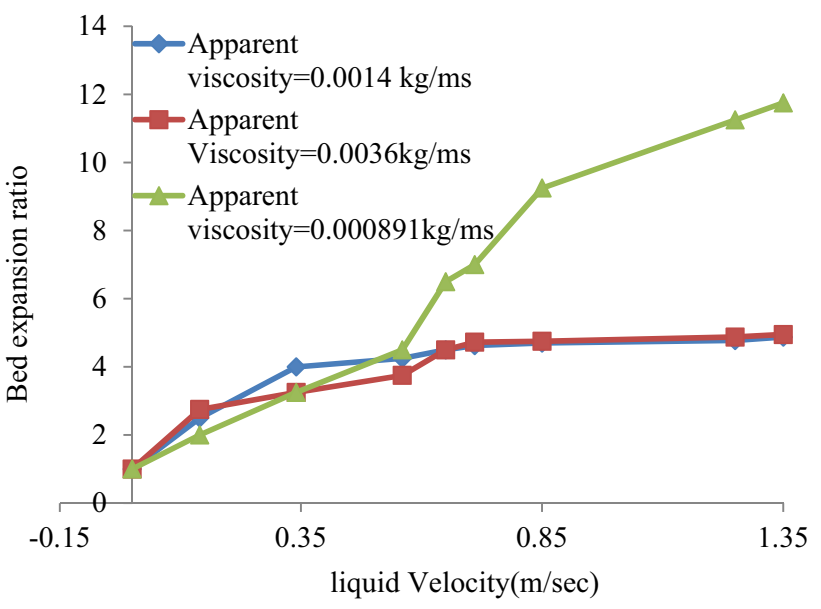

Fig. 6 Effect of apparent liquid viscosity on bed expansion profiles in 8 degrees HDPE

The bed voidage was affected by increasing liquid velocity as sown in Fig. 5. By increasing the liquid velocity, the turbulence of the solids increased, and voidage increased, as in other words, at different apparent viscosity of inlet liquids, the voidage decreased with increasing viscosity of liquids.

From Fig. 6, it was found that the bed expansion ratio will increase with an increase in different apparent viscosity of the liquid, but at different apparent viscosity of liquids, the bed expansion ratio varied. The reason could be because of lower turbulence and the transition of the flow moment of the solid regime at high apparent viscosity of the liquid. In other words, the solid holdup decreases drastically with increasing liquid viscosity in the higher range of apparent liquid viscosity.

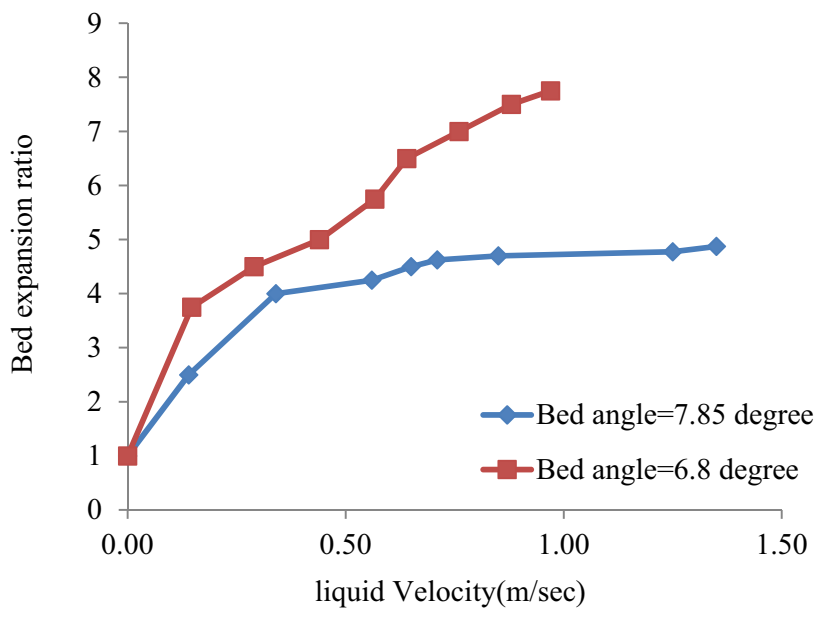

Fig. 7 Comparison of bed expansion profiles in different angles of beds

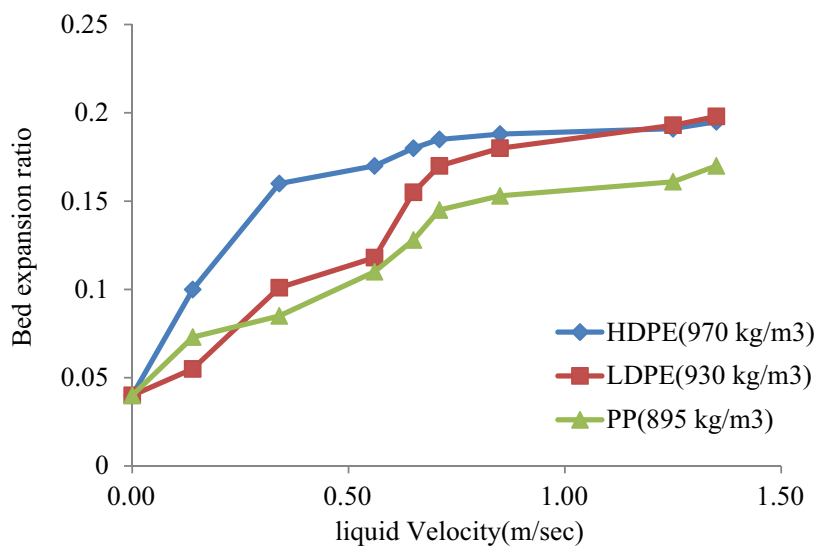

Fig. 8 Comparison of bed expansion profiles for different densities of solids

The consequences of liquid velocity on bed expansion ratio at different angles of fluidized beds can be seen in Fig. 7. It was found that the bed expansion ratio was higher in $a=7.85$ than in $a=6.8$ angle of fluidized beds. The reason is that in the high-range angle of the bed, the surface area inside the bed is extensive, and pressure phenomena low compared to lower-range angle of bed so that the bed expansion is higher in 6.8 angles of the fluidized bed.

The effect of liquid velocity on bed expansion at an angle of 7.85 degree inverse fluidized bed at different densities of HDPE, LDPE, and PP particles can be seen in Fig. 8. Note in this figure that bed expansion of different particles increases with increasing liquid velocity in all the instances studied. In other words, the bed expansion was high for the high density of particles compared to the lower density of particles; the reason behind this is increased liquid velocity from the top of the bed and 
at the same time buoyancy force phenomenon working in the opposite direction to the bed expansion from the bed. There the particles should overcome these forces and expand downwards of the bed.

\subsection{Minimum fluidization velocity studies}

It is estimated from the correlation obtained from the experimental data relating to the minimum fluidization velocity, Archimedes number, and density difference.

Correlation

$U_{\mathrm{mf}}=a[\operatorname{Ar}]^{b}\left[\frac{\left(\rho_{\mathrm{l}}-\rho_{\mathrm{s}}\right)}{\rho_{\mathrm{l}}}\right]$

where $a=8.464 * 10^{-3}, b=0.459, c=0.301 \times 10^{4}<\operatorname{Ar}<8 \times 10^{4}$.

Some of the models were used to estimate the minimum fluidization velocity and were compared with experimental results.

Khani et al.

$\operatorname{Re}_{\mathrm{mf}}=10.396(\mathrm{Ar})^{0.367}\left(\frac{d_{\mathrm{p}}}{D_{0}}\right)^{0.889}\left(\frac{\varepsilon_{0}}{\phi_{\mathrm{s}}}\right)^{-0.731}(\cos \alpha)^{-10.437}$ for $\alpha>4.5$

where $\operatorname{Re}_{\mathrm{mf}}$ is the modified Reynolds number, Ar is Archimedes number, $a$ is the angle in the reactor.

Biswal et al.

$U_{\mathrm{mf}}=\frac{-A 1+\operatorname{SQRT}\left(A 1^{2}+4 B 1 C 1\right)}{2 B 1}$

where $A_{1}=\cos \left(\frac{\alpha}{2}\right)\left[3717 \tan (\alpha)^{-0.47} \frac{\mu\left(1-\varepsilon_{0}\right)^{2}}{g d_{p}^{2} \varepsilon_{0}} \frac{r_{0}\left(r_{1}-r_{0)}\right.}{r_{1}}\right]$,

$B 1=\cos \left(\frac{\alpha}{2}\right) \frac{\rho_{l}\left(1-\varepsilon_{0}\right)}{g d_{\mathrm{p}} \varepsilon_{0}^{3}} \frac{r_{0}\left(r_{1}^{3}-r_{0}^{3}\right)}{3 r_{1}^{3}}, C 1=r_{1}\left(1-\varepsilon_{0}\right)\left(\rho_{1}-\rho_{\mathrm{s}}\right)$,

$r_{0}, r_{1}=$ bottom and top radii of the bed, $\varepsilon_{0}=$ bed voidage, $\mathrm{D}_{\mathrm{p}}=$ diameter of particles, $\rho_{\mathrm{l}}=$ liquid density, $\rho_{\mathrm{s}}=$ solid density.

Modified Ergun equation:

$A u_{\mathrm{mf}}+B \frac{r_{0}}{r_{1}} u_{\mathrm{mf}}^{2} \cdot-\left(1-\varepsilon_{\mathrm{mf}}^{2}\right)\left(\rho_{l}-\rho_{\mathrm{s}}\right) g \frac{r_{0}^{2}+r_{0} r_{1}+r_{1}^{2}}{3 r_{0}^{2}}$

where $A=150 \frac{\left(1-\varepsilon_{m f}^{2}\right)}{\varepsilon_{m f}^{3}} \frac{\mu_{l}}{\left(\phi_{s} d_{p}\right)^{2}}, B=1.75\left(\frac{1-\varepsilon_{m f}}{\varepsilon_{m f}}\right) \frac{\rho_{l}}{\phi_{s} d_{p}}, \mu_{1}$ is the liquid viscosity, $\phi_{\mathrm{s}}$ is the solids porosity.

Effect of apparent liquid viscosity on minimum fluidization velocity:

The effect of initial bed heights on minimum fluidization velocity for different apparent viscosity of liquids is shown in Fig. 9. From the figure, it was observed that the minimum fluidization velocity was independent of the

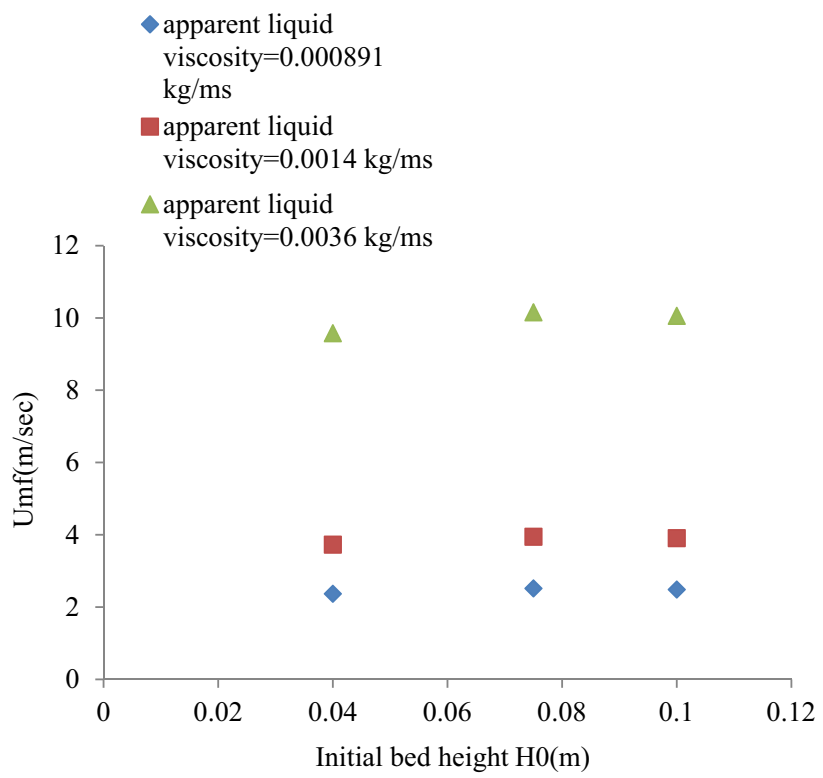

Fig. 9 Comparison of minimum fluidization velocity profiles for different apparent viscosity of the liquid

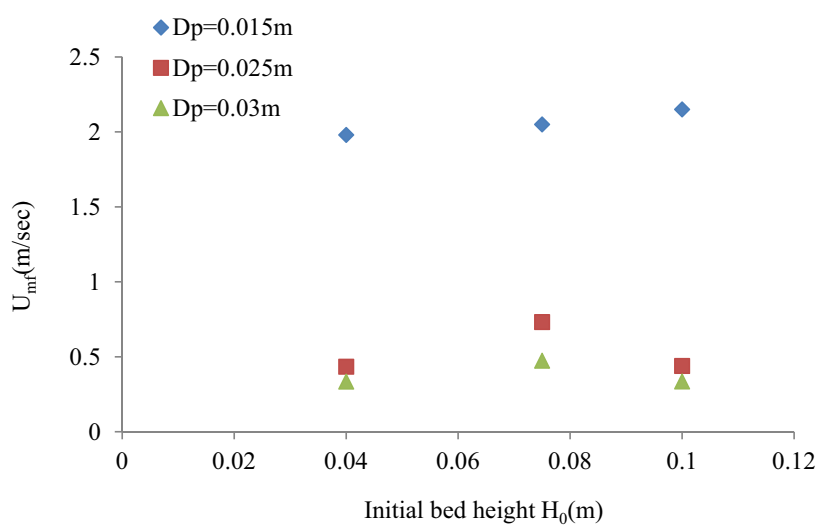

Fig. 10 Comparison of minimum fluidization velocity profiles for different diameter of solids

weight of materials, but it varied for different viscosities of the liquid. For the high viscous nature of liquids, the minimum fluidization velocity was very high, the reason being that the contact area of each particle with water was high in high viscosity of liquids so that it needed more velocity to lift the particles from the top of the bed downwards.

From Fig. 10, it is observed that the minimum fluidization velocity is independent of the initial bed heights, but it varied for different diameters of particles. It was high for the low diameter of particles and low for the high diameter of particles; the reason was that low-diameter particles 


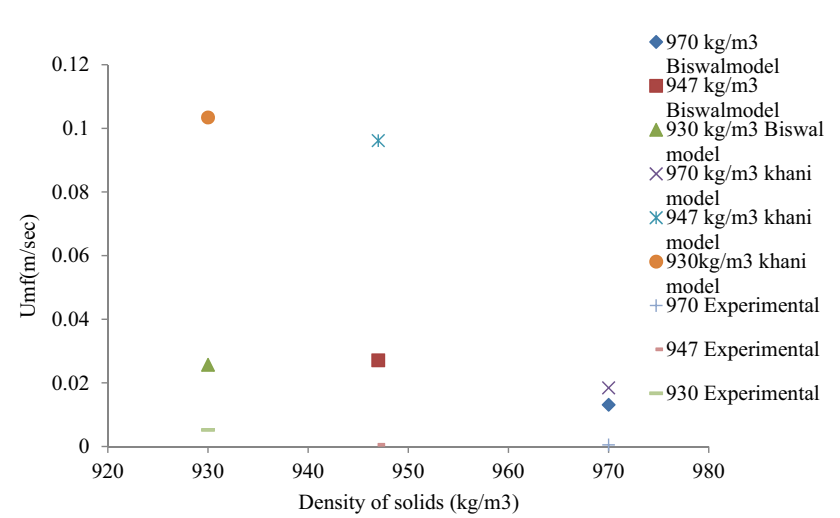

Fig. 11 Comparison of minimum fluidization velocity profiles for different models with a density of solids

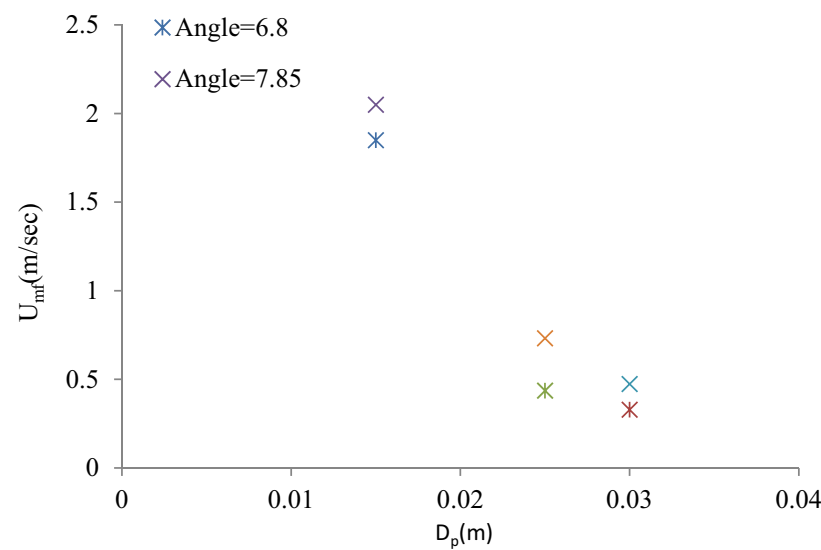

Fig. 12 Comparison of minimum fluidization velocity profiles for a different angles of beds with a density of solids

floated on the water, and it needed high velocity to lift the particles compared to particles of high diameter.

The effect of the diameter of particles on minimum fluidization velocity for different models from the literature and experimental data is shown in Fig. 11. It was found that the minimum fluidization velocity was higher for low-density particles and low for high-density particles. The reason is that the phenomenon of the bouncy force was acting in the opposite direction to the gravitational force, i.e., in an upward direction. The graph for the abovementioned models shows different minimum fluidization velocities. This was because, in those different models, the bed was considered in some of the equations, and bed angle was considered in some of the equations.

Figure 12 shows the effects of solids on diameter on minimum fluidization velocity at different angles of beds.
As expected, the Umf value attains the lowest value with an increase in the diameter of solids. The reason was that the solid holdup increases with a diameter, so it needs low Umf to move the particles from the top of the bed. Umf was also varied with different angles for fluidized beds for the large angle of beds; Umf was low when compared to the low angle of the fluidized bed. The reason is the increase in the cross-sectional area, so it needs immense velocity to lift the particles.

\subsection{Measurement of bed voidage, bed volume and pressure drop}

To understand the characteristics in the inverse tapered fluidized bed, based on the mathematical model of bed expansion and it was observed that the pressure drop has increased the addition of solids weight. It was considered that the bed voidage in each bed increment could be determined by the correlation of Wen and Yu:

$\varepsilon_{\mathrm{s}}=\left[\frac{18 N_{\mathrm{Re}}+2.7 N_{\mathrm{Re}}^{1.687}}{N_{\mathrm{Ga}}}\right]^{0.213}$

where $N_{\mathrm{Ga}}=\frac{\left[d_{\mathrm{p}}^{8} \rho_{f}\left(\rho_{f}-\rho_{\mathrm{s}}\right) g\right]}{\mu^{2}}$

The pressure drop over on each bed increment was determined by force needed to support the bed in a gravitational field:

$\Delta p=\left(1-\varepsilon_{\mathrm{s}}\right)\left(\rho_{f}-\rho_{\mathrm{s}}\right) g h$

The solid volume in the bed can be determined by a simple material balance around each increment.

$\Delta V_{\mathrm{s}}=(1-\varepsilon) A h=(1-\varepsilon) \Delta V$

The total bed volume is determined when a summation of the incremental solids equals the volume of the original solid with the bed at rest:

$\sum(1-\varepsilon) \Delta V=\left(1-\varepsilon_{0}\right) V_{0}$

\subsubsection{Effect of apparent liquid viscosity on bed voidage}

The effect of Reynolds number on bed voidage is represented in Fig. 13. By increasing liquid velocity, the Reynolds number also increased, and the bed voidage increased. The reason was that at increased velocities, the solids 


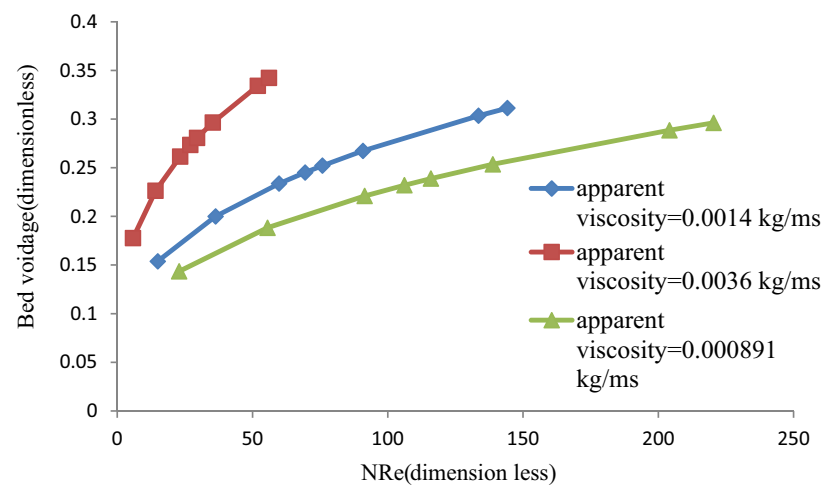

Fig. 13 Comparison of bed voidage profiles for different viscosity of liquids with Reynolds number (angle $=6.8$ )

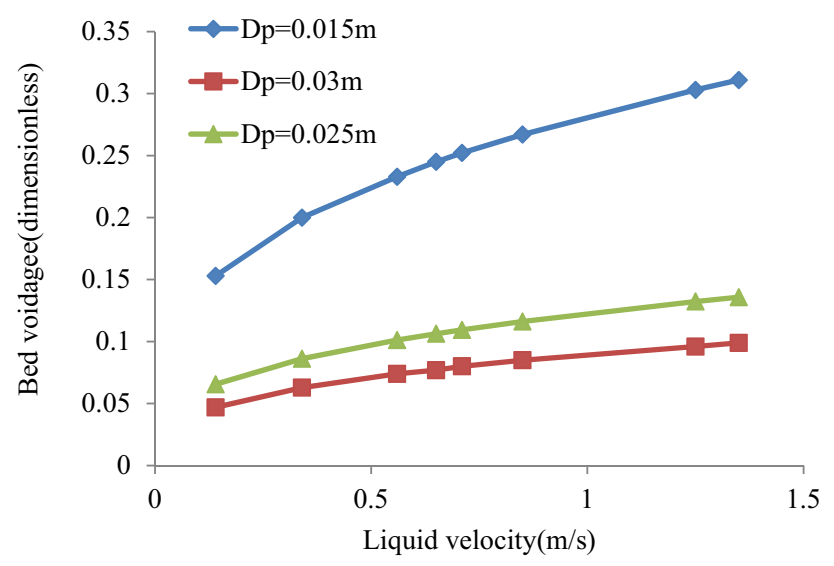

Fig. 14 Comparison of bed voidage profiles for different diameter of solids with a velocity of liquid (angle $=6.8$ )

holdup increased. The bed voidage was also dependent on the apparent viscosity of liquid; by increasing the apparent viscosity of liquid, bed voidage was also increased due to Reynolds number, which was inversely proportional to the Reynolds number.

The effect of particle diameter on the bed voidage graphical representation is shown in Fig. 14. By increasing the liquid velocity, the bed voidage increased with different diameters of solids. For the large diameter of particles, the voidage was low because of which a considerable amount of buoyancy force was needed to lift the solids.

Comparing experimental pressure drop and calculated pressure drop, there was some difference as shown in Fig. 15. The reason was that while doing the experiments, some leakages and delay of time to note the readings occurred.

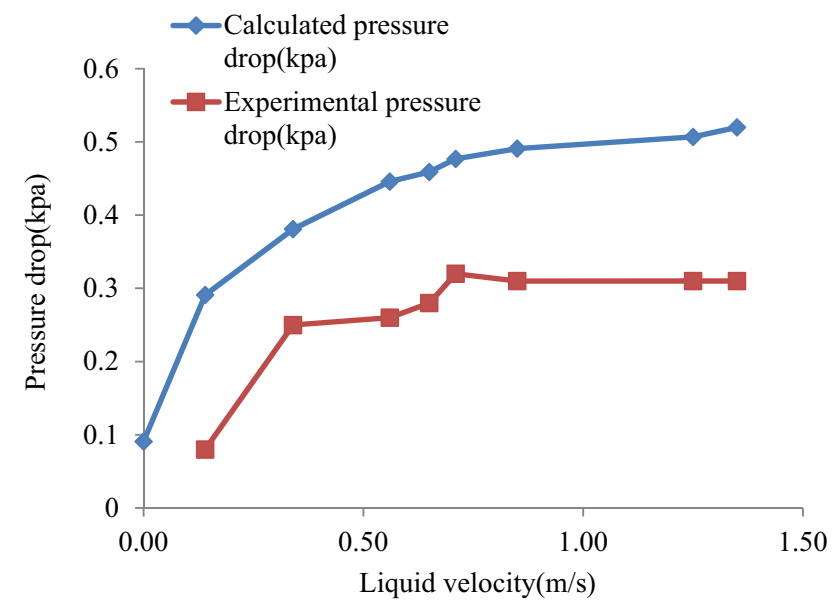

Fig. 15 Comparison of experimental pressure drop with calculated pressure drop on the velocity of liquid (angle $=6.8$ )

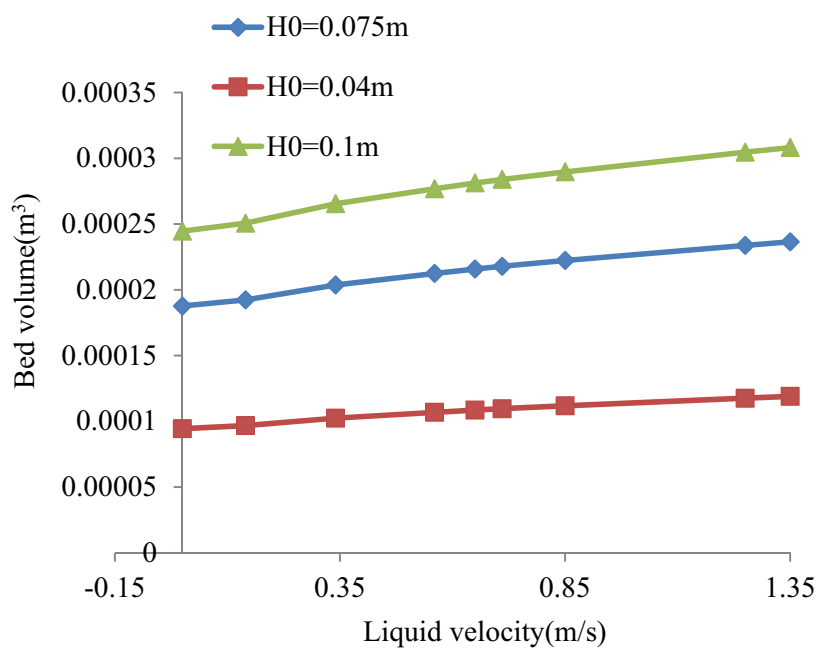

Fig. 16 Comparison of bed volume profiles for different initial bed heights with the velocity of liquid (angle 6.8)

Table 1 Geometry of acrylic tapered inverse fluidized beds

\begin{tabular}{llll}
\hline Bed height $(\mathrm{m})$ & Top diameter $(\mathrm{m})$ & $\begin{array}{l}\text { Bottom diam- } \\
\text { eter }(\mathrm{m})\end{array}$ & $\begin{array}{l}\text { Tapered } \\
\text { angle } \\
(\mathrm{a})\end{array}$ \\
\hline 0.59 & 0.09 & 0.25 & 7.85 \\
0.59 & 0.075 & 0.22 & 6.8 \\
\hline
\end{tabular}

\subsubsection{Effect of initial bed height on total bed volume}

The effect of initial bed height on the bed volume with liquid velocity is shown in Fig. 16. By increasing the liquid 
Table 2 Physical properties of solid and liquid

\begin{tabular}{llllllll}
\hline S. No & Type of Material & Size $(\mathrm{m})$ & $\begin{array}{l}\text { Density } \\
\left(\mathrm{kg} / \mathrm{m}^{3}\right)\end{array}$ & Weight $(\mathrm{kgs})$ & Initial bed heights $(\mathrm{m})$ & Temperatures & Liquid viscosity $(\mathrm{kg} / \mathrm{m} \mathrm{s})$ \\
\hline 1 & HDPE & 0.015 & 970 & $0.08,0.159,0.206$ & $0.04,0.075,0.1$ & $45,63,80$ & $0.000891,0.0014,0.0036$ \\
2 & PP & 0.025 & 947 & $0.08,0.159,0.206$ & $0.04,0.075,0.1$ & $45,63,80$ & $0.000891,0.0014,0.0036$ \\
3 & LDPE & 0.03 & 930 & $0.08,0.159,0.206$ & $0.04,0.075,0.1$ & $45,63,80$ & $0.000891,0.0014,0.0036$ \\
\hline
\end{tabular}

Table 3 Symbols and levels of independent parameters were used in response surface methodology

\begin{tabular}{|c|c|c|c|c|c|c|c|c|c|c|c|}
\hline \multirow[t]{2}{*}{ Symbol } & \multirow[t]{2}{*}{ Parameters } & \multirow[t]{2}{*}{ Units } & \multirow{2}{*}{$\begin{array}{l}\text { No of } \\
\text { levels }\end{array}$} & \multicolumn{8}{|l|}{ Levels } \\
\hline & & & & 1 & 2 & 3 & 4 & 5 & 6 & 7 & 8 \\
\hline A & Temperature & ${ }^{\circ} \mathrm{C}$ & 4 & 33 & 45 & 63 & 80 & & & & \\
\hline B & Apparent viscosity & $\mathrm{Kg} / \mathrm{ms}$ & 3 & 0.00089 & 0.0014 & 0.0036 & & & & & \\
\hline C & Density of solids & $\mathrm{Kg} / \mathrm{m}^{3}$ & 3 & 930 & 945 & 970 & & & & & \\
\hline D & Bed angle & Degree & 2 & 6.8 & 7.85 & & & & & & \\
\hline$E$ & Velocity of liquid & $\mathrm{m} / \mathrm{sec}$ & 8 & 0.14 & 0.34 & 0.56 & 0.65 & 0.71 & 0.85 & 1.25 & 1.35 \\
\hline
\end{tabular}

velocity, the bed volume increased, and it was varied for different initial bed heights. The reason was the weight of the solids bed area which increased from the top to bottom of the reactor.

Developing of Empirical model by using Response surface methodology (RSM):

Response surface method (RSM) used different statistical, graphical, and mathematical techniques to broaden, enhance, or optimize procedures, and it was also used for modeling and evaluation of problems if the response variables were encouraged through several unbiased variables (Tables 1, 2).

Surface response methodology (RSM) data modeling used an inbuilt utility of design expert package (version 9 ) in the present work to derive the regression models in terms of different process parameters like velocity of liquid, temperature of liquid, viscosity of liquid, the density of solids and different angles of reactors. This model equation was used to get the influence of process parameters on the bed expansion ratio through the reactor. The confidence level of data was kept at 0.95 for the bed expansion ratio.

Correlated equation of mean residence time in terms of factors:
Table 4 ANOVA table for response surface

\begin{tabular}{lrrl}
\hline Source & $\begin{array}{r}\text { Sum of } \\
\text { squares }\end{array}$ & \multicolumn{1}{l}{$\begin{array}{l}\text { Value } \\
\text { Model }\end{array}$} & $\begin{array}{l}p \text {-value } \\
\text { Prob }>F\end{array}$ \\
\hline A-temperature & 7940.42 & 134.18 & $<0.0001$ \\
B-apparent viscosity & 364.24 & 148.39 & $<0.0001$ \\
C-density & 208.28 & 84.86 & $<0.0001$ \\
D-bed angle & 3.41 & 1.39 & $<0.0001$ \\
E-velocity & 3778.84 & 1539.53 & 0.2393 \\
AB & 24.62 & 10.03 & $<0.0001$ \\
AC & 18.86 & 7.68 & 0.0016 \\
AD & 21.42 & 8.73 & 0.0058 \\
AE & 31.73 & 12.93 & 0.0033 \\
BC & 51.61 & 21.03 & 0.0004 \\
BD & 30.91 & 12.59 & $<0.0001$ \\
BE & 12.44 & 5.07 & 0.0004 \\
CD & 9.06 & 3.69 & 0.0248 \\
CE & 18.36 & 7.48 & 0.0552 \\
DE & 3.95 & 1.61 & 0.0064 \\
\hline
\end{tabular}

Linear regression $\left(R^{2}\right) 0.90 R^{2}$ adjusted 0.8832

Bed expansion ratio $\left(H / H_{0}\right)=90.327-0.717 *$ Temperature of liquid $+17,575.5 *$

Apparent viscosity of liquid $-0.0892 *$ Solids density $-14.52 *$ Bed angle $-23.82 *$

Velocity of liquid $-9.88^{*}$ Temperature of liquid*Apparent viscosity of liquid $+6.147 *$

$10^{\wedge} 0.004-$ Temperature of liquid ${ }^{*}$ Solids density* $+0.02 *$ Temperature of liquid*

Bed angle $+0.033^{*}$ Temperature of liquid*velocity of liquid $-15.47^{*}$ Apparent viscosity of liquid*

Solids density - $376.37 *$ Apparent viscosity * Bed angle - $322.91 *$ Apparent viscosity * Velocity

$+0.014 *$ Solids density*Bed angle $+0.027 *$ Solids density $*$ Velocity of liquid

$+0.04 *$ Bed angle $*$ Velocity of liquid 
Equation (13) was developed in terms of independent parameters. The corresponding $p$ and $F$ values, the linear regression coefficient, and the adjusted regression coefficients are represented in Table 4. It was observed from Table 3 that the values of the linear regression coefficient $\left(R^{2}\right)$ and the adjusted $\left(R^{2}\right)$ were almost the same in magnitude. Furthermore, the value of probability was found to be $F$, which signifies that the independent parameters were trustworthy. Moreover, the results from the model equation were that the bed angle affects very less while the velocity of the liquid, the apparent viscosity of the liquid, the temperature of the liquid, and the density of solids affect bed expansion ratio more. The effects of the different parameters on the bed expansion ratio are shown in Figs. 17, 18, 19, 20 and 21.

From Fig. 17, it was observed that by increasing the temperature of the liquid, which was continuous, the reactor bed expansion ratio also increased, the viscous nature of liquid decreased, and the solid holdup was high.
Fig. 17 Effect of temperature design expert software on bed expansion ratio by

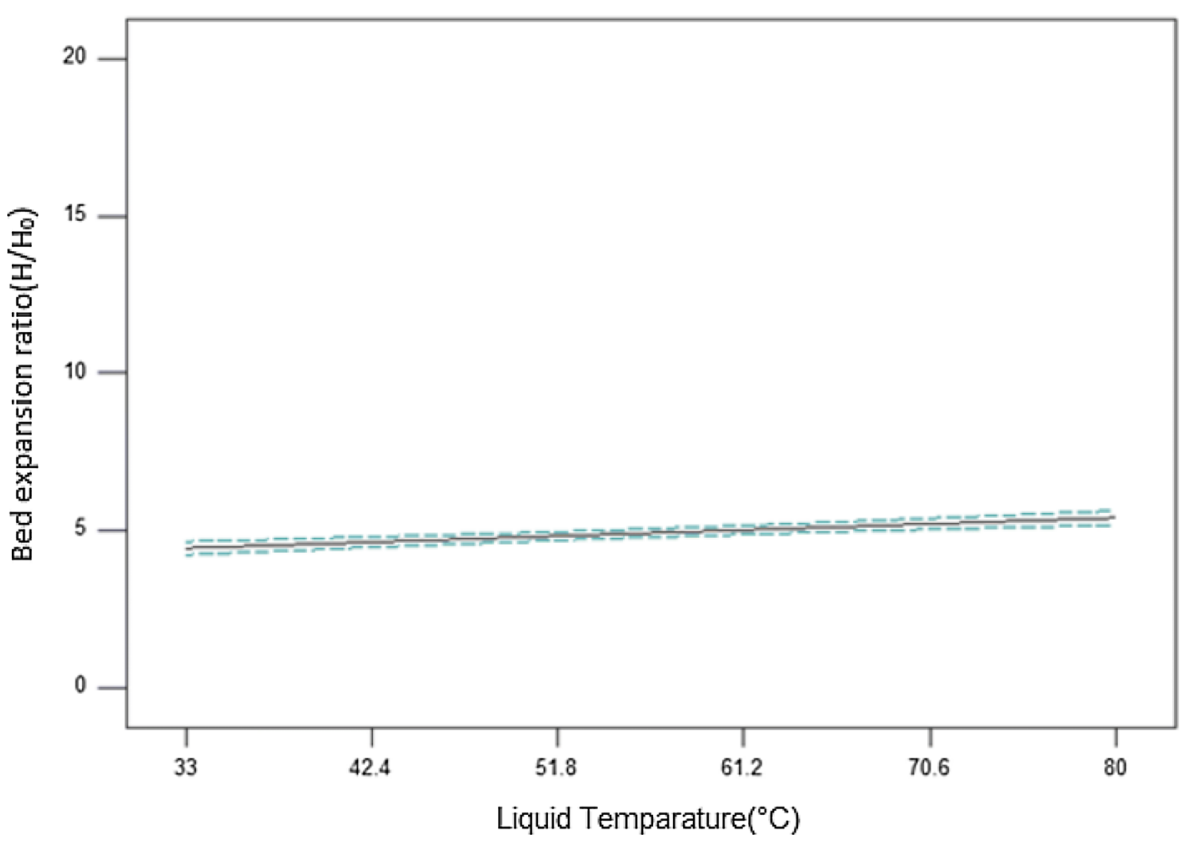

Fig. 18 Effect of apparent liquid viscosity on bed expansion ratio by design expert software

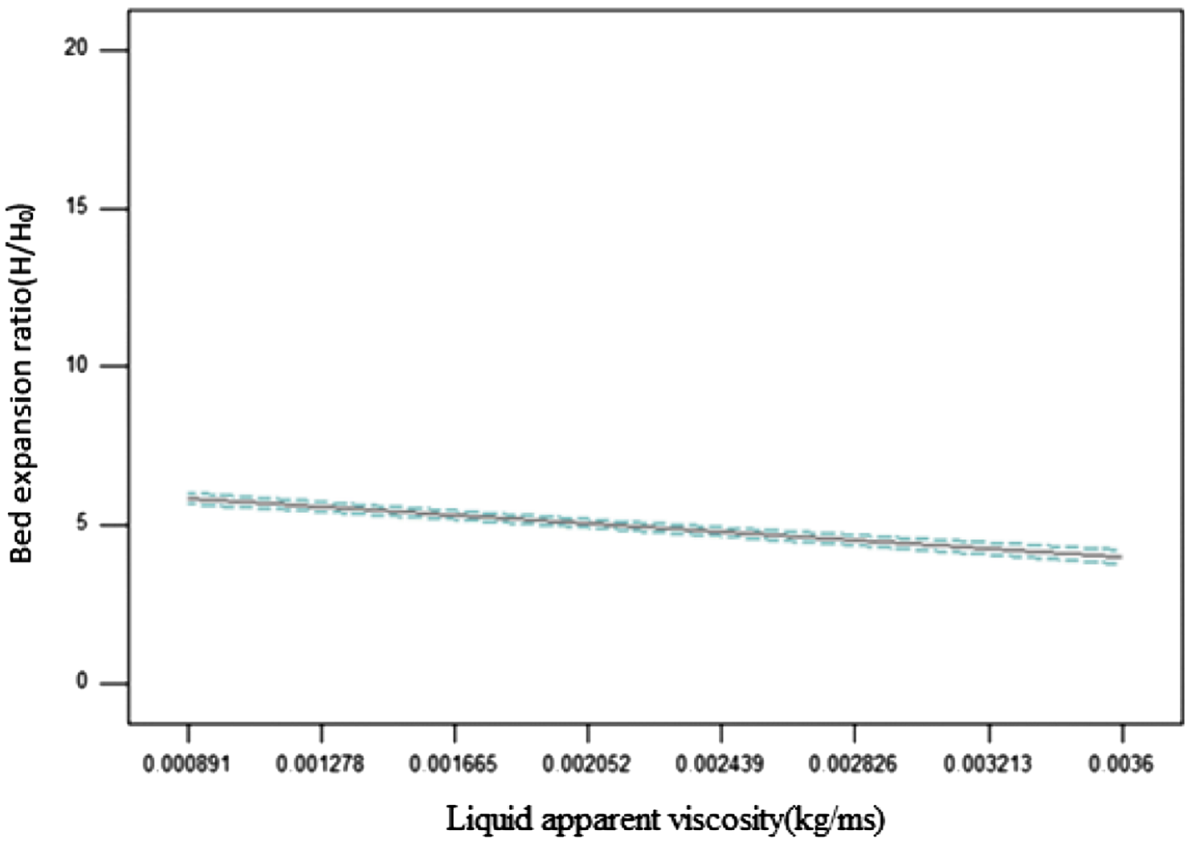


Fig. 19 Effect of solids density on bed expansion ratio by design expert software
Fig. 20 Effect of liquid velocity on bed expansion ratio by design expert software
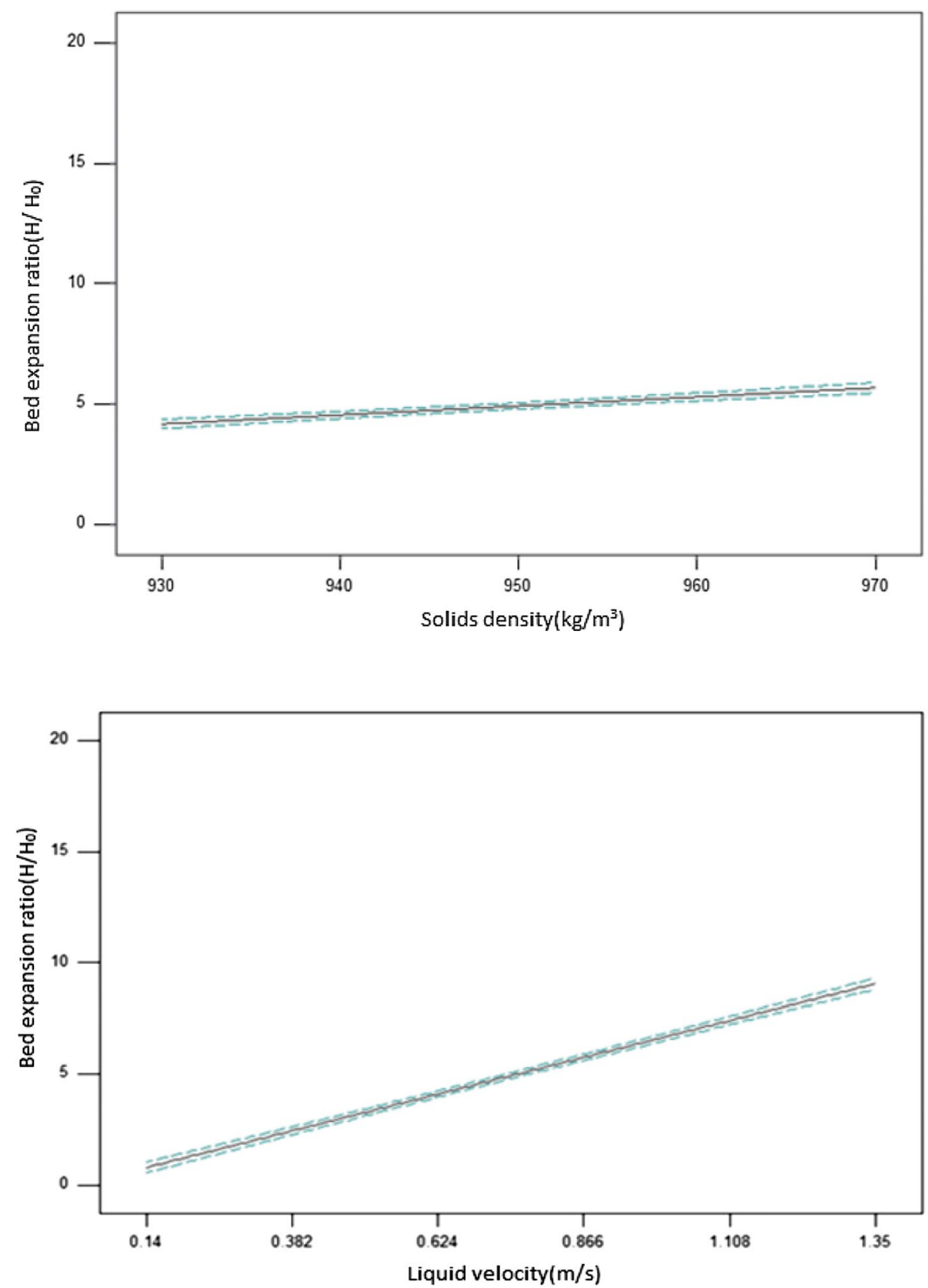

The effect of apparent liquid viscosity on the bed expansion ratio is observed in Fig. 18. It was found that the bed expansion ratio was decreased by increasing liquid apparent viscosity. The reason was that the solid holdup phenomenon was less for high viscous liquids.

The effect of solid density on the bed expansion ratio is shown in Fig. 19. It was found that the bed expansion ratio increased by increasing solid density. The reason was that the solid holdup phenomenon was high for high-density solids because it will easily overcome the buoyancy force acting in an upward direction.
The effect of liquid velocity on the bed expansion ratio is shown in Fig. 20. It was found that the bed expansion ratio increased by increasing liquid velocity. The reason was that the solid holdup phenomenon was high for the high velocity of liquids.

From Fig. 21, it was observed that the experimental and predicted bed expansion ratio values were almost the same. 
Fig. 21 Comparison of actual and predicted bed expansion ratios by design expert software

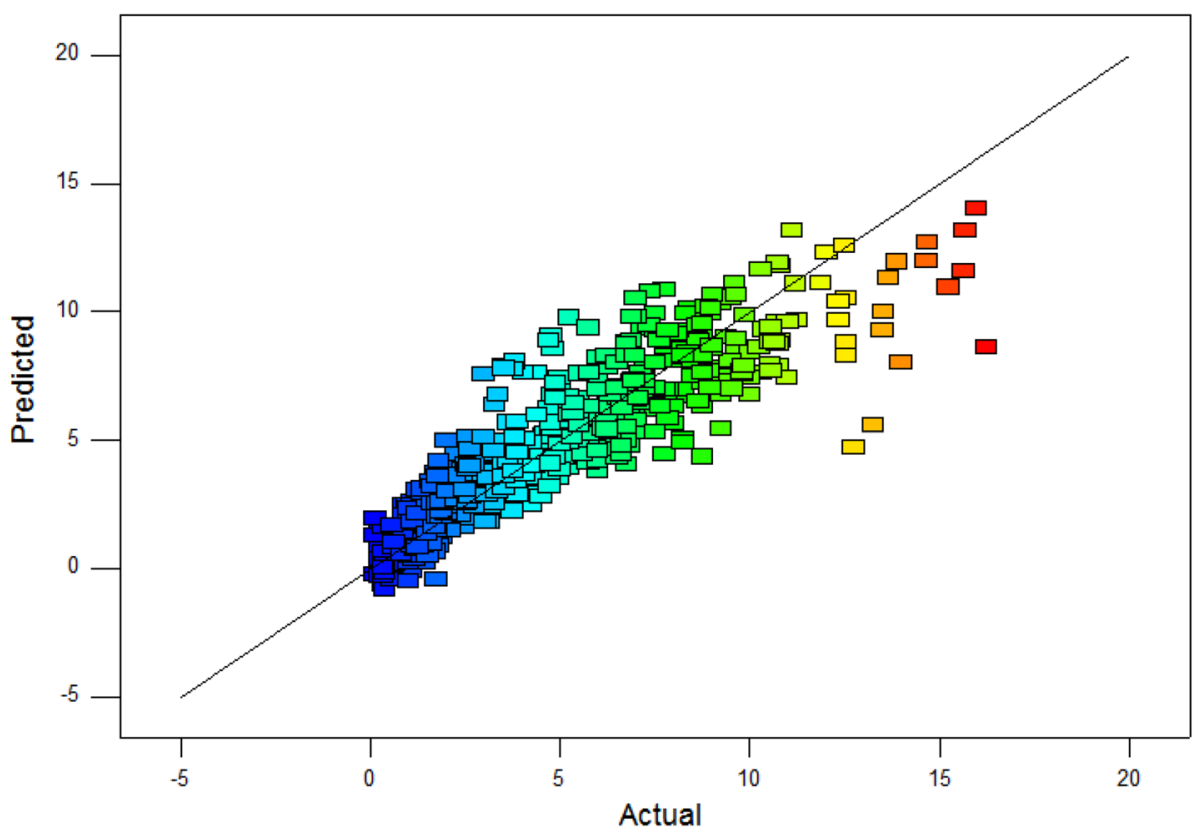

\section{Conclusions}

The heat transfer coefficient increases with increasing liquid velocity in two-phase, tapered inverse fluidized bed. The heat transfer coefficient was higher for high-density particles (HDPE) than for low-density particles (LDPE) and (PP). The heat transfer coefficient reached its maximum value with increasing particle density. The bed expansion ratio was higher for high temperatures and decreased by increasing liquid viscosity. The bed expansion ratio also depends on the density of solids and the angle of beds. The minimum fluidization velocity was higher for high apparent viscosity of liquids and lower for low apparent viscosity of liquids, and the minimum fluidization velocity depends on the density of solids, diameter, and angle of fluidized beds. The bed voidage increased with increasing liquid velocity, while the Reynolds number depends on the diameter of particles. The volume of solids increased with increasing liquid velocity and varied with initial bed heights. From the design expert software, the bed expansion ratio was found to depend on almost all the independent parameters.

\section{Compliance with ethical standards}

Conflict of interest The authors declare that they have no conflict of interest.

\section{References}

1. Wang D, Silbaugh T, Pfeffer R, Lin YS (2010) Removal of emulsified oil from water by inverse fluidization of hydrophobic aerogels. Powder Technol 203:298-309. https://doi.org/10.1016/j. powtec.2010.05.021

2. Alvarado-Lassman A, Rustrián E, García-Alvarado MA et al (2008) Brewery wastewater treatment using anaerobic inverse fluidized bed reactors. Bioresour Technol 99:3009-3015. https://doi. org/10.1016/j.biortech.2007.06.022

3. Anantharaman A, Cocco RA, Chew JW (2018) Evaluation of correlations for minimum fluidization velocity (Umf) in gassolid fluidization. Powder Technol 323:454-485. https://doi. org/10.1016/j.powtec.2017.10.016

4. Scott CD, Hancher CW, Shumate SE (2013) A tapered fluidized bed as a bioreactor. Enzym Eng XVIII:255-261. https://doi. org/10.1007/978-1-4757-5163-5_29

5. Lakshmi ACV, Balamurugan M, Sivakumar M et al (2000) Minimum fluidization velocity and friction factor in a liquid-solid inverse fluidized bed reactor. Bioprocess Eng 22:461-466. https ://doi.org/10.1007/s004490050759

6. Zhou D, Dong S, Wang H, Bi HT (2009) Minimum fluidization velocity of a three-phase conical fluidized bed in comparison to a cylindrical fluidized bed. Ind Eng Chem Res 48:27-36. https:// doi.org/10.1021/ie8001974

7. Sur DH, Mukhopadhyay M (2017) Process aspects of three-phase inverse fluidized bed bioreactor: a review. J Environ Chem Eng 5:3518-3528. https://doi.org/10.1016/j.jece.2017.06.052

8. Campos-Díaz KE, Bandala-González ER, Limas-Ballesteros $R$ (2012) Fluid bed porosity mathematical model for an inverse fluidized bed bioreactor with particles growing biofilm. J Environ Manage 104:62-66. https://doi.org/10.1016/j.jenvm an.2012.03.019

9. Hamdad I, Hashemi S, Rossi D, Macchi A (2007) Oxygen transfer and hydrodynamics in three-phase inverse fluidized beds. Chem Eng Sci 62:7399-7405. https://doi.org/10.1016/j.ces.2007.08.066 
10. Geng S, Qian Y, Zhan J et al (2017) Prediction of solids residence time distribution in cross- flow bubbling fluidized bed. Powder Technol 320:555-564. https://doi.org/10.1016/j.powte c.2017.07.085

11. Comte MP, Bastoul D, Hebrard G et al (1997) Hydrodynamics of a three-phase fluidized bed-the inverse turbulent bed. Chem Eng Sci 52:3971-3977. https://doi.org/10.1016/S0009 -2509(97)00240-6

12. Sabarunisha Begum S, Radha KV (2014) Hydrodynamic behavior of inverse fluidized bed biofilm reactor for phenol biodegradation using Pseudomonas fluorescens. Korean J Chem Eng 31:436-445. https://doi.org/10.1007/s11814-013-0260-z

13. Krishnaiah K, Guru S, Sekar V (1993) Hydrodynamic studies on inverse gas-liquid-solid fluidization. Chem Eng J 51:109-112. https://doi.org/10.1016/0300-9467(93)80017-I

14. Rajasimman M, Karthikeyan C (2009) Performance of inverse fluidized bed bioreactor in treating starch wastewater. Front Chem Eng China 3:235-239. https://doi.org/10.1007/s1170 5-009-0020-0

15. Renganathan T, Krishnaiah K (2004) Stochastic simulation of hydrodynamics of a liquid-solid inverse fluidized bed. Ind Eng Chem Res. https://doi.org/10.1021/ie0304513

16. Lee DH, Epstein N, Grace JR (2000) Hydrodynamic transition from fixed to fully fluidized beds for three-phase inverse fluidization. Korean J Chem Eng 17:684-690. https://doi.org/10.1007/ BF02699118

17. Karamanev DG, Nikolov LN (1992) Bed expansion of liquid-solid inverse. AIChE J 38:1916-1922

18. Fan LS, Muroyama K, Chern SH (1982) Hydrodynamic characteristics of inverse fluidization in liquid-solid and gas-liquid-solid systems. Chem Eng J 24:143-150. https://doi.org/10.1016/03009467(82)80029-4

19. Cho YJ, Park HY, Kim SW et al (2002) Heat transfer and hydrodynamics in two- and three-phase inverse fluidized beds. Ind Eng Chem Res 41:2058-2063. https://doi.org/10.1021/ie0108393

20. Tawfik MHM, Refaat Diab M, Mohmed Abdelmotalib H (2019) An experimental investigation of wall-bed heat transfer and flow characteristics in a swirling fluidized bed reactor. Appl Therm Eng 155:501-507. https://doi.org/10.1016/j.appltherma leng.2019.04.022

21. Guo Z, Sun Z, Zhang N et al (2019) Computational study on fluid flow and heat transfer characteristic of hollow structured packed bed. Powder Technol 344:463-474. https://doi. org/10.1016/j.powtec.2018.11.101

22. Toh KHB, Lim EWC (2019) Dimensionless numbers and correlations for characterizing heat transfer in a pulsating fluidized bed. Appl Therm Eng 153:448-462. https://doi.org/10.1016/j.applt hermaleng.2019.03.039

23. Jia D, Bi X, Lim CJ et al (2019) Heat transfer in a tapered fluidized bed of biomass particles with pulsed gas flow. Particuology 42:2-14. https://doi.org/10.1016/j.partic.2018.01.007

24. Teng MXW, Lim EWC (2018) Heat transfer from an immersed tube in a pulsating fluidized bed. Appl Therm Eng 143:326-339. https://doi.org/10.1016/j.applthermaleng.2018.07.087

25. Sahu AK, Raghavan V, Prasad BVSSS (2018) Temperature effects on hydrodynamics of dense gas-solid flows: Application to bubbling fluidized bed reactors. Int J Therm Sci 124:387-398. https ://doi.org/10.1016/j.ijthermalsci.2017.10.028

Publisher's Note Springer Nature remains neutral with regard to jurisdictional claims in published maps and institutional affiliations. 